\title{
Aproximación al modo subjuntivo del español desde una perspectiva multivariable
}

\author{
Approach to the Subjunctive Mood in Spanish \\ from a Multivariable Perspective \\ Aproximação ao modo subjuntivo do espanhol \\ desde uma perspectiva multivariável
}

\begin{abstract}
Alberto Cueva Lobelle ${ }^{1}$
\section{Resumen}

Este artículo analiza el modo subjuntivo del español desde una perspectiva multivariable y holística. Específicamente, analiza qué características pragmáticas, semánticas y sintácticas presentan las construcciones con subjuntivo. Para responder la pregunta se analizaron cien construcciones de subjuntivo a la luz de algunos conceptos de la Gramática Funcional de Dik (1997). Los datos fueron analizados a partir de un conjunto de rasgos que se ubicaron en una escala de prototipicidad. La determinación de los rasgos se hizo con base en un análisis preliminar de los datos, con la información reportada en la bibliografía y con base en el modelo teórico adoptado.
\end{abstract}

\section{Palabras clave}

subjuntivo; subordinadas; modalidad; rasgos

\section{Abstract}

This paper analyzes the subjunctive mood in Spanish from a multivariable and holistic perspective. More specifically, we analyze the pragmatic, semantic and syntactic characteristics of subjunctive constructions. To this end, we analyzed one hundred subjunctive constructions in light of some concepts of Dik's Functional Grammar (1997). The data was analyzed from a set of traits located on a prototypical scale. The traits were determined based on a preliminary analysis of the data, with the information reported in the literature and based on the theoretical model adopted.

\section{Keywords}

subjunctive; subordinates; modality; features

\section{Resumo}

Este artigo analisa o modo subjuntivo do espanhol desde uma perspectiva multivariável e holística. Especificamente, analisa quais características pragmáticas, semânticas e sintáticas apresentam as construções no subjuntivo. Para responder à pergunta, analisaram-se cem construções no subjuntivo sob alguns conceitos da Gramática Funcional de Dik (1997). Os dados foram analisados a partir de um conjunto de características organizadas em nível de prototipicidade. A determinação dessas características baseou-se em uma análise preliminar dos dados, com as informações apresentadas na bibliografia e com base no modelo teórico adotado.

\section{Palavras-chave}

subjuntivo; subordinadas; modalidade; caraterísticas

Artículo recibido el 8 de enero de 2017 y aprobado el 10 de enero de 2018

1 Profesor asistente. Universidad Nacional de Colombia. Correo electrónico: aclobelle@gmail.com 


\section{Introducción}

El subjuntivo en español es el modo que emplean los hablantes para expresar el deseo (Bello, 1847); la no aserción o la no realidad (Ridruejo, 1999; Alarcos Llorach, 1994; Gili Gaya, 1994), la probabilidad o virtualidad (Sastre, 1999; RAE, 2009) y la no factualidad (cf. Pérez, 1999). A partir de estos criterios, es posible explicar oraciones como las que se presentan en 1-4:

(1) Ojalá venga pronto.

(2) Probablemente no venga mañana / vs. Viene mañana.

(3) Le ordeno que venga mañana.

(4) Aunque hubiera llovido, habríamos ido a verte.

En (1) se expresa un deseo, lo que implica que no es un hecho o una aserción. En (2) se expresa una probabilidad, lo que anula su carácter factual. En (3), la orden expresada por el emisor es un hecho factual pero lo ordenado no, pues no depende de la voluntad del emisor sino de un tercero. En (4) se expresa un hecho irreal.

Vásquez (2013) cuestiona la noción de irrealis, presentada por Alarcos, en cuanto muestra ejemplos donde la acción es real y aparece en subjuntivo. Señala que el subjuntivo es un modo que aparece en oraciones subordinadas y que tiene un carácter ambivalente en tanto expresa valores propios del indicativo y del potencial.

Pérez (1999, p. 3318) identifica tres tipos de contextos en los que puede aparecer el subjuntivo:

[...] puede aparecer en contextos dubitativos, en los que el hablante no se compromete o niega el valor de verdad de la oración; en contextos volitivos en los que la oración subordinada señala el objetivo que se pretende conseguir, y en contextos temáticos, en los que se supone el valor de verdad de la oración subordinada, pero se otorga una función informativa secundaria al contenido de esta oración.

También se constata en la bibliografía que algunos tipos de oraciones se construyen con subjuntivo: las finales, las condicionales concesivas o las condicionales irreales, como se ilustra en (5)-(7).

(5) Te regalo este dinero para que compres un vestido.

(6) Aunque llores todo el día, no te doy permiso.

(7) Si hubieras creído eso, te hubieras equivocado.

Esta constatación es compatible con los criterios propios del subjuntivo, pues en las oraciones finales se expresa un evento que aún no se ha realizado (probabilidad), en las oraciones condicionales concesivas (6) e irreales (7), el rasgo de no factualidad resulta determinante.

Obsérvese que en las oraciones (1)-(3) y (5), está presente el rasgo de posterioridad o futuro, que está asociado también con el subjuntivo ( $c f$. RAE, 2009; Ridruejo, 1999); en cambio en las oraciones (4) y (6), este rasgo está ausente. Esto parece configurarse en un hecho problemático con miras a una generalidad.

En las oraciones relativas, el subjuntivo, presenta además de los rasgos de inexistencia, el de especificidad o inespecificidad ( $c f$. Pérez, 1999). Se construye con indicativo la oración que denota un objeto específico (8) y con subjuntivo lo inespecífico (9).

(8) Busca un libro que trata sobre la felicidad.

(9) Busca un libro que trate sobre la felicidad.

En (8) el emisor sabe de qué libro se trata; en (9), invita al receptor a buscar en un conjunto de libros.

Se asocia, por lo general, la determinación con la especificidad y la indeterminación con lo inespecífico.

La negación expresada a través del adverbio no o por medio de otra marca induce el subjuntivo en la mayoría de contextos. Y esto es así pues se niega la factualidad y, en muchos casos, con la negación se niega toda la predicación subordinada.

(10) Pienso que es una buena idea.

(11) No pienso que sea una buena idea.

En (11) lo importante no es si es o no una buena idea, sino lo que piensa el emisor.

La estrecha relación el modo y la modalidad ha sido señalada por Palmer (1986), Moreno (1991), 
Ridruejo (1999) y por la RAE (2009). La modalidad se considera una característica más general y se entiende como la actitud del hablante frente al contenido proposicional que expresa (Gili Gaya, 1994; Sastre, 1999). Esta modalización puede ser expresada de diversas maneras, entre ellas a través del modo verbal. Para Moreno (1991):

La oposición indicativo/subjuntivo aparece en diversas lenguas y puede realizar la oposición entre varias modalidades, podemos distinguir entre una modalidad realis y una modalidad irrealis. Se pueden realizar respectivamente mediante los modos indicativo y subjuntivo. La modalidad realis suele consistir en una actitud del hablante ante lo que enuncia de asunción de la verdad o presunción de la realidad o bien una actitud positiva ante un hecho posible. El indicativo suele realizar esta modalidad y mediante él el hablante se compromete a asumir como verdadero aquello que él enuncia. La modalidad irrealis se suele expresar mediante el subjuntivo; ahora la actitud del hablante no es la anterior, sino es algo más variada ya que hay muchos modos de irrealidad, pero solo uno de realidad. Puede tratarse de que el hablante no asuma que lo que dice está en consonancia con la realidad o que asuma que es poco probable, o que se trate de algo no asumido por hipotético o simplemente que se trate de algo falso, o que se trate de una actitud negativa ante un hecho; puede también tratarse de una orden, consejo o prohibición. (p. 316).

Es interesante ver que para Moreno todos los usos del subjuntivo están mediados por la modalidad realis o irrealis, y que esta se asocia a la actitud del hablante. Entonces, el subjuntivo puede presentar un hecho real pero lo determinante parece ser la perspectiva del hablante.

Esta mirada del subjuntivo coincide en parte con lo afirmado por otros investigadores ( $c f$. Ridruejo, 1999; RAE, 2009), para quienes el subjuntivo es el modo a través del cual el emisor expresa su poco compromiso frente a lo anunciado o una evaluación (negativa o positiva) frente a lo dicho.

(12) Me parece increíble que haya venido.

(13) Simplemente, me dijeron que renunciara.
Gracias a este rasgo es posible explicar construcciones en subjuntivo que aluden a un hecho factual en el pasado -y en el que se esperaría indicativocomo el que se presenta en (12). El subjuntivo reflejaría más una valoración que un hecho. En (13) es evidente que el hablante no quería renunciar.

Así mismo, se destaca en la bibliografía la relación entre nociones semánticas asociadas con este modo (deseo, duda, voluntad, inexistencia) y una serie de verbos que se suelen relacionar con el subjuntivo. Por ejemplo:

Eligen subjuntivo un gran número de predicados que expresan VOLUNTAD O INTENCIÓN. Pueden ser, en primer lugar, verbales, como aspirar (a), decidirse (a), desear, esforzarse (por), luchar (por), pretender, procurar, querer, tratar (de), etc. (RAE, 2009, p. 1879).

Un enfoque diferente y que resulta bastante esclarecedor, como se verá más adelante, es el de Igualada (1989, p. 649), quien parte de la hipótesis de que "el subjuntivo se diferencia del indicativo por su incapacidad para expresar tiempo", la cual comprueba a partir de las alternancias indicativo/ subjuntivo y sobre todo a partir de la alternancia entre infinitivo y subjuntivo, por cuanto el infinitivo no tiene marcas de tiempo, lo mismo pasaría con el subjuntivo, en ejemplos del tipo Me gusta ir allál Me gusta que vayas allá o Enciende la luz para ver mejor/Enciende la luz para que veas mejor.

A pesar de que hay abundantes estudios sobre el subjuntivo español, no se encuentra en la bibliografía una mirada unitaria de este modo verbal. De otra parte, en todos los estudios hay una serie de usos del subjuntivo que no parecen tener una explicación adecuada: por una parte, algunos que admiten tanto indicativo como subjuntivo sin aparente cambio de significado (14), y otros que aparecen como inexplicables. Algunos ejemplos de estos usos del subjuntivo son:

(14) Me molesta que no te des/das cuenta de lo que sucede.

(15) Me alegro de que goces de tan buena salud. 
(16) Le dieron el premio, aunque no se lo mereciera/lo merecía.

(17) Le pedí que me escribiera.

(18) La culpa de que estemos en esta situación es de María.

(19) Consiguió que subieran los impuestos indirectos.

La presente investigación intentó explicar usos del subjuntivo como los presentados en (14)-(19) y dar una visión general y más coherente de este modo verbal, teniendo como referente teórico la gramática funcional; particularmente, se empleó el enfoque de Simon Dik (1997), quien integra los niveles pragmático, semántico y sintáctico para estudiar un fenómeno lingüístico. Este modelo se complementó con el paradigma de la gramática estructural funcional presente en los trabajos de los investigadores españoles Alarcos Llorach (1994), Moreno Cabrera (1991) y Bosque (1990), en tanto ellos (a diferencia de Dik) han investigado el subjuntivo español.

La pregunta que guio la investigación fue: ¿Qué características sintácticas, semánticas y pragmáticas muestra el subjuntivo español?

\section{Metodología}

Para resolver la pregunta se analizaron cien ejemplos de construcciones con subjuntivo que se encontraron en gramáticas españolas. Se hizo un acercamiento multivariado y holístico, que consiste en integrar los niveles sintáctico, semántico y pragmático y emplear un conjunto de rasgos que se ponen en una línea de prototipicidad.

Como hipótesis de partida se plantea que la combinación y jerarquización de rasgos puede dar una imagen más adecuada del subjuntivo español, y que es posible comprender la mayor parte de los usos del subjuntivo ubicando los criterios en una escala de prototipicidad, donde unos usos de subjuntivo activan unos rasgos y opaca otros.

De acuerdo con esta mirada se puede hablar de construcciones con subjuntivo prototípicas, menos prototípicas o más alejadas del campo del subjuntivo: en un extremo se encuentra el elemento o ejemplo más representativo, y en el otro, el menos representativo; en el medio, hay escalas o zonas de transición posibles. La noción de prototipo sirve para agrupar elementos nocionalmente cercanos y simplificar la descripción lingüística.

La perspectiva que se adoptó para el análisis coincide con lo que se conoce en la bibliografía como análisis multivariable (cf. Bickel, 2010; Lizárraga y Mora-Bustos, 2010), según el cual, a partir de una serie de variables, se estudia cualquier tipo de construcción.

Un antecedente importante de esta metodología se encuentra en el trabajo sobre transitividad elaborado Hopper y Thompson (1980) quienes establecen diez parámetros para hablar de la transitividad; ellos son: número de participantes (ha de haber al menos dos para que haya transitividad), kinesis (ha de haber denotación de una acción para que haya transitividad), aspecto (una acción orientada a su terminación -acción télica- es más transitiva que una atélica), puntualidad (las acciones que no poseen una fase intermedia entre su comienzo y su finalización son las más transitivas), volitividad (acción consciente del primer actor sobre el segundo), afirmación (esta tiene mayor grado de transitividad que la negación), modo (una acción real es más transitiva que una irreal), agencia (los participantes con características de agente -con control- incrementan la transitividad), afectación del objeto (el mayor grado de afectación del objeto incrementa la transitividad) e individuación del objeto (un objeto concreto, específico, singular, da mayor grado de transitividad que uno que no lo es). La tipificación de estos parámetros es gradual y la concurrencia de estos parámetros determina el mayor o menor grado de transitividad que presenta una construcción oracional.

Un estudio similar realizó Mora-Bustos (2013) quien a partir de los rasgos de fuerza ilocutiva, tiempo, foco, posición, simetría, orden, conector y tipo de oración analiza qué tan similares son las construcciones consideradas tradicionalmente como subordinadas adverbiales. Como resultado, el autor presenta distintas agrupaciones de estas 
oraciones, de acuerdo con conjuntos específicos de rasgos. Así, una oración final puede estar asociada con unas oraciones según el rasgo de simetría/ asimetría y con otras según el rasgo de orden.

Como se señala en Ochoa (2009, p. 64) diversos autores como García-Miguel (1995), Lazard (2002), Mora-Bustos (2005) e incluso Hopper y Thompson (1980, pp. 286-287) han tratado de reagrupar los rasgos, ya sea a través de criterios sintácticos o semánticos. En el presente artículo los rasgos se agrupan por los niveles de la lengua: sintácticos, semánticos y pragmáticos.

Para el establecimiento de los rasgos se hizo inicialmente un análisis exploratorio de los datos y de allí se obtuvieron unos primeros rasgos; después, se hizo un segundo análisis con base en los rasgos reportados en la revisión bibliográfica y en el modelo teórico adoptado. Es importante aclarar que algunos conceptos de la gramática funcional de Dik (1997) no resultaron productivos cuando se analizaron los datos, es decir, no fue posible discriminar los usos a partir de estos conceptos; es el caso de valencia, pues los predicados que se construyen en subjuntivo pueden ser monovalentes, bivalentes o trivalentes.

De la combinación de los dos procedimientos presentados anteriormente, se establecieron los siguientes rasgos:

\section{Rasgos sintácticos}

Número de sujetos: con este rasgo se alude a cuántos sujetos gramaticales (uno o dos) intervienen en las construcciones de subjuntivo. Se entiende por sujeto gramatical el sintagma que concuerda en número y persona con el verbo.

Control: se entiende como la capacidad que tiene el sujeto gramatical central para decidir la realización de lo que se describe a través del subjuntivo. Según Dik (1997), quien controla tiene la capacidad de determinar si el estado de cosas descrito por el predicado verbal sucederá o no.

Tiempo: hace referencia por un lado a la relación entre el tiempo del evento principal y el de la situación específica descrita en la subordinada, y por otro, el tiempo entre el momento del acto de habla y el del verbo. El evento descrito por el subjuntivo puede ser simultáneo, anterior o posterior al otro evento o al acto de habla.

Aspecto: a través de este rasgo se indica la cualidad aspectual del verbo (aktionsart). Se sigue aquí la clasificación dada por Vendler (1957) en cuatro tipos: estados, actividades, realizaciones y logros. Las actividades y realizaciones implican unas fases, a diferencia de los estados y los logros; los estados y las actividades no presuponen una acción télica (punto final); lo que sí ocurre con las realizaciones y logros.

Tipo de oración: a través de este rasgo se hace alusión a si la oración codifica una afirmación, negación, interrogación u orden. Así mismo, se hace referencia a si la oración es simple o compuesta. Cuando es compuesta, se analiza si es coordinada, yuxtapuesta o subordinada.

Conector subordinante: con este rasgo se alude no solo a la presencia o ausencia de un conector entre el verbo principal y la oración introducida por el subjuntivo, sino a si es prescindible o no.

Estilo directo $o$ indirecto: hace referencia al modo como se cuenta lo que otro ha dicho. Con el estilo directo se reproduce el mensaje tal como se ha escuchado: "El presidente afirmó: 'las elecciones no serán en marzo"'. Con el estilo indirecto se reproduce el contenido del mensaje con las palabras del emisor: "El presidente afirmó que las elecciones no serán en marzo".

\section{Rasgos semánticos}

Estatus de los constituyentes: se refiere a si la construcción que aparece con subjuntivo es un constituyente obligatorio (argumento) o si es opcional (satélite).

Realidad vs. Irrealidad: se alude a si el evento descrito por la subordinada ocurre, ocurrió u ocurrirá en un mundo real. Es decir, representa o denota un hecho (factualidad) o si, por el contrario, lo que se presenta es solo una probabilidad o irrealidad.

Especificidad vs. Inespecificidad: se hace alusión a si el evento descrito es determinado o no y a si los objetos presentados, por ejemplo, en una oración 
relativa son conocidos o no por el emisor. Alude también a una cierta indeterminación temporal.

\section{Rasgos pragmáticos}

Actitud del emisor: consiste en cómo el emisor transmite o evalúa el contenido proposicional que se expresa a través del subjuntivo. Muestra la actitud y las emociones personales del hablante en relación con el contenido transmitido o con el acto comunicativo. Específicamente comprende dos aspectos: la valoración negativa o positiva del hecho enunciado y el grado de compromiso del emisor frente a lo sucedido: asume alguna responsabilidad o toma distancia (indiferencia).

Atenuación: el subjuntivo se usa en ocasiones para mitigar la intención comunicativa del emisor.

\section{Resultados}

\section{Rasgos sintácticos}

Sujetos gramaticales: en las construcciones con subjuntivo aparece en forma prototípica dos sujetos involucrados: el sujeto de la oración principal y el de la oración subordinada. Ejemplos se muestran en $(20)$ y $(21)$

(20) Me quejo de que no me hagan caso.

(21) Dio la orden de que se acercaran.

En (20) y (21) hay dos sujetos distintos: en (20) el yo para el verbo principal y ellos para el verbo subordinado. Lo mismo ocurre en (21): él y ellos.

Se encuentra en forma no prototípica construcciones con la apariencia de un solo sujeto gramatical:

(22) No creo que (yo) sea inteligente sino disciplinada.

(23) No dejes para mañana lo que puedas hacer hoy.

En (22) y (23) hay dos sujetos gramaticales, pero son los mismos para cada evento: yo en (22) y tú en (23).

Este rasgo de tipo gramatical (sujeto) se fusiona en ocasiones con un rasgo pragmático que alude a la presencia de los interlocutores del acto comunicativo: el emisor y el receptor.
En (21) es posible pensar en dos sujetos gramaticales y un interlocutor: el emisor. En (23) es evidente que hay un emisor quien se dirige a un receptor. De otra parte, obsérvese que en (22) parece que el emisor está respondiendo a una aseveración anterior del tipo: "eres muy inteligente". Con el subjuntivo, el emisor toma distancia de lo dicho.

Control y volitividad: prototípicamente en las construcciones con subjuntivo, el sujeto de la oración principal no tiene control sobre el segundo sujeto, por ende no puede determinar si el evento sucederá o no. En (21) es posible que ellos no se acerquen.

Esta falta de control por el primer sujeto puede explicar que el evento se produzca al margen de él o a su pesar, como se muestra en (20): al yo no le hacen caso y en eso precisamente radica su queja, o en (24) donde es evidente que el primer sujeto no quería que subieran los impuestos, pero no tenía el control para evitarlo:

(24) Lamento que hayan subido los impuestos.

En un número reducido de ejemplos, el esquema de control se invierte: el primer sujeto gramatical tiene control sobre el estado de cosas descrito por el subjuntivo:

(25) Dio motivo para que llegaran tarde.

El subjuntivo parece explicarse por la falta de control (o voluntad) del sujeto de la subordinada: no fue por su culpa que llegaron tarde. Obsérvese un ejemplo similar con el sintagma culpa presente en (18):

(18) La culpa de que estemos en esta situación es de María.

Así mismo, los verbos causativos generan un esquema invertido de control:

(26) Las peculiaridades de España llevan a que el Barroco encuentre ahí un terreno estupendamente abonado.

En (26), el sujeto de la oración principal provoca el evento descrito en el subjuntivo.

Este rasgo de control se fusiona con el mismo rasgo pragmático, señalado anteriormente: presencia 
del emisor y el receptor. Volviendo al ejemplo (23), el emisor no puede controlar si el receptor dejará o no las cosas para mañana.

Tiempo: en la mayoría de subjuntivos analizados, el tiempo del subjuntivo es posterior al tiempo del evento principal y al evento de habla. Ejemplos típicos son (21) y (23): en (21) el hecho de acercarse es posterior a la orden; en (23) la sugerencia precede a lo sugerido.

No obstante, hay subjuntivos que expresan un evento anterior, como se ve en (24): el lamento aparece después de la subida de los impuestos.

También se encontró, para los estados, una relación que hemos llamado atemporal entre los dos eventos, en el sentido de que el evento está indeterminado temporalmente: parece pertenecer al presente simultáneo del acto de habla, a un pasado reiterativo o incluso a un futuro.

(27) No me gusta que conduzcas tan rápido.

Este valor parece explicar algunas de las alternancias entre indicativo y subjuntivo:

(28) Comprendo que necesita tiempo/comprendo que necesite tiempo.

Es claro en (27) que el tú ha conducido en el pasado, conduce en el presente del acto de habla y seguramente conducirá en el futuro. En (28) parece que el evento se restringe al ahora con indicativo y a un tiempo futuro o indeterminado con el subjuntivo.

Obsérvese que este rasgo es coherente con la idea de indeterminación propia del subjuntivo, idea que aparece con mayor claridad en algunas oraciones de relativo:

(29a) Necesita una empleada que trate bien a los niños.

(29b) Necesita la empleada que trata bien a los niños.

En (29a) no se conoce a dicha empleada, la referencia es indeterminada; en (29b) se hace referencia a una empleada específica.

Aspecto: la mayoría de los subjuntivos analizados pertenecen a la tipología actividades; no obstante, se encuentran también ejemplos de estados (15) y de realizaciones (24), estas últimas se presentan por lo general cuando el tiempo del evento del subjuntivo es pasado o simultáneo al acto de habla.

(15) Me alegro de que goces de tan buena salud.

(24) Lamento que hayan subido los impuestos.

El rasgo durativo resulta esencial para comprender el subjuntivo pues aparece en la mayoría de los casos: en (15) el gozar de buena salud no está circunscrito a un momento puntual.

La falta de telicidad, propia de las actividades y estados, explica por qué muchos subjuntivos son intransitivos, tienen un solo constituyente obligatorio o están usados en sentido absoluto.

(30) Nunca sucedía que bailara con jóvenes.

En (30), bailar es un predicado intransitivo y tiene un solo constituyente obligatorio. Estos dos rasgos se relacionan de manera indirecta con la atemporalidad e inespecificidad que caracteriza a varios usos del subjuntivo.

Tipo de oración: la mayoría de los subjuntivos analizados codifican una aseveración, lo que no implica que aparezcan interrogativas e incluso exclamativas:

(31) Eso hizo que al llegar a Delphi me sintiera mejor.

(32) ¿Usted cree que sea muy difícil ver al papa?

(33) ¡Maldita sea mi suerte!

De otra parte, la mayoría de subjuntivos aparecen en oraciones subordinadas ya sean completivas o adverbiales. Las oraciones completivas aparecen en función de complemento directo (véase a modo de ejemplo, las oraciones (3), (11), (13)) o sujeto (algunos ejemplos se pueden ver en (12), (14), (15)). Las oraciones adverbiales prototípicas son las finales con subjuntivo (ejemplo (5)).

En efecto, el contenido prospectivo de los verbos conjugados en las oraciones finales hace que no admitan el indicativo. Su carácter intencional implica sujetos agentes animados no correferenciales en la oración principal y subordinada. La acción 
volitiva y la representación de los hechos como futuro no realizado en la oración subordinada final hace que sus formas verbales se inclinen claramente hacia el modo de la subjetividad y de la irrealidad.

No obstante, podemos encontrar oraciones finales donde, en cierta medida, su significado prospectivo e intencional quedaría difuminado. Se trata de oraciones finales que reflejan más bien la actitud del emisor ante lo enunciado en la oración principal a modo de recomendación, llamada de atención o advertencia. Por ejemplo:

(34 a) Hay que darle su merecido, para que aprenda a respetar.

(34b) Hay que darle su merecido. ¡Para que aprenda a respetar!

Estas oraciones subordinadas tienen la peculiaridad de presentarse siempre en un grupo entonativo aparte, a la manera de añadidos fácilmente conmutables por el mandato expresado en un modo imperativo.

El subjuntivo es un modo sumamente ligado a la expresión de la finalidad que incluso se pueden encontrar formas subjuntivas con la preposición para elidida.

(35) Lee antes de juzgar, (para) que no te engañen.

Ello es debido a que la expresión de la finalidad queda consustancialmente ligada a la subjetividad del emisor ante hechos no realizados y su voluntad, desconfianza o deseo para que sucedan o no. De hecho, pueden aparecer oraciones finales con verbo conjugado en subjuntivo que no cumplen el criterio de la presencia de la conjunción subordinante. Ejemplos típicos se ven en (36) y (37):

(36) Abriga al niño, no se vaya a resfriar.

(37) Suéltame el brazo, no piensen que somos novios.

Conector: la mayoría de construcciones con subjuntivo están introducidas por un conector; especialmente se usa el conector que, al introducir oraciones completivas, o formas con que como a pesar de que; también aparece si, aunque y sus variantes. De estos conectores podemos ratificar la idea de que la mayoría de oraciones en las que aparece el subjuntivo son subordinadas.

Un rasgo diferenciador (aunque no excluyente) a la hora de clasificar las conjunciones coordinantes frente a las subordinantes es la prescindibilidad de las primeras frente a las segundas. Prototípicamente, no se puede prescindir del conector subordinante; aunque pueda darse este hecho en la expresión de la causalidad mediante la conjunción subordinante porque y la conjunción ilativa pues.

En la mayoría de casos no es posible prescindir del conector, pues genera agramaticalidad, lo que a veces sí es posible con indicativo:

En estos casos se ha cambiado la oración subordinada a oración simple yuxtapuesta.

(14a) Me molesta que no te des cuenta de lo que sucede. ${ }^{\star}$ Me molesta: no te des cuenta de lo que sucede.

(14b) Me molesta que no te das cuenta de lo que sucede. / Me molesta: no te das cuenta de lo que sucede.

De otra parte, el conector condiciona en algunas ocasiones la presencia del subjuntivo. Veamos de nuevo el ejemplo (4):

(4) Aunque hubiera llovido, habríamos ido a verte.

En este ejemplo, la conjunción concesiva aunque introduce un contraargumento débil, de tal manera que, a pesar de que se da a entender que entre el tipo de eventualidad presentado por la oración subordinada y el presentado por la oración subordinante existe cierto grado de incompatibilidad; dicha incompatibilidad no alcanza a impedir que se cumpla lo expresado por el verbo principal. Este contraargumento es, a su vez, expresado por el pretérito pluscuamperfecto de subjuntivo hubiera llovido, una forma compuesta retrospectiva que indica anterioridad o coexistencia respecto del punto de referencia constituido por el verbo de la oración principal y que podría haber tenido lugar en otras circunstancias. El núcleo de la oración principal habríamos ido es un tiempo condicional compuesto y se refiere a un proceso ya inactual, incierto y condicionado dentro del ámbito del pasado. De hecho, la totalidad de la 
oración compleja apunta a una situación no posible en el tiempo presente.

Estilo directo o indirecto: aparecen numerosas construcciones de subjuntivo en estilo indirecto cuando en el estilo directo se encuentran en imperativo. Recordemos que el cambio de estilo directo a indirecto afecta a la deixis personal, espacial y temporal. Por lo tanto, al centramos en los morfemas de tiempo verbal podemos comprobar fácilmente cómo la cita indirecta pierde su temporalidad en provecho de aquella que le impone el verbo de la expresión introductora. De esta manera, se establece un paralelismo entre la forma imperativa que aparece en el momento de la enunciación del discurso directo y la correspondiente forma anclada en las coordenadas temporales del discurso indirecto en pretérito imperfecto de subjuntivo. Ejemplos típicos se muestran en (38) y (39).

(38) Juan le pidió a su hermana que vinera pronto.

/ Juan le pidió a su hermana: "Ven pronto".

(39) Les dijo que se olvidaran de esa petición.

Obviamente, en la reproducción del discurso mediante estilo indirecto también pueden aparecer gran cantidad de construcciones en subjuntivo a la manera de muñecas rusas (es decir, subordinadas unas a otras), siempre y cuando la forma verbal introductoria esté en presente de subjuntivo, pretérito imperfecto de subjuntivo o pretérito perfecto de subjuntivo.

(40) Mi tía me pidió que dijera en la asamblea que ordenasen a los conserjes que dejaran pasar a los invitados.

Este rasgo se correlaciona con el hecho de que el subjuntivo aparece en oraciones subordinadas y con rasgos pragmáticos como la falta de compromiso de parte del hablante frente a lo enunciado, ya que lo dicho no son palabras suyas sino de otros: al ponerlo en estilo indirecto y al ser dicho por un tercero la falta de compromiso se resalta.

\section{Rasgos semánticos}

Estatus de los constituyentes: los subjuntivos pueden ser tanto constituyentes obligatorios, como opcionales. En el primer caso, se trata de constituyentes que funcionan como primer o segundo argumento del predicado principal, ya sea de estructuras con un solo predicado, como las presentes en (1), (2) y (33), o en estructuras donde el subjuntivo está subordinado a un predicado principal, como las de (17), (19) y (27): (17) y (19) son segundo constituyente y (27), primero.

Cuando se trata de constituyentes opcionales se codifican diversos valores semánticos; por ejemplo, la concesividad, finalidad y condicionalidad. Véase los ejemplos (4), (5) y (7), respectivamente. Con excepción de la finalidad, la mayoría de los valores semánticos asociados a constituyentes no obligatorios se pueden expresar con ambos modos: indicativo y subjuntivo. La presencia del subjuntivo se asocia con la ausencia del rasgo de factualidad y la presencia de la probabilidad; este el caso de (4) donde es claro que no llovió, pero la lluvia era un posible impedimento para hacer la visita.

Realidad vs. Irrealidad. La mayoría de las construcciones con subjuntivo denotan un evento hipotético, posible (32), no factual o irreal. Hay, sin embargo, un número de usos del subjuntivo que denotan un evento real, que sucedió en el pasado.

(41) ignoraba que hubiera entrado en la sala.

En (41) es evidente que alguien entró en la sala. El subjuntivo se explica por el verbo principal (ignorar) que determina todo el conjunto, es decir, que tiene un alcance sobre el otro predicado. De otra parte, su presencia se explica por razones pragmáticas: rompe las expectativas del emisor.

\section{Rasgos pragmáticos}

Actitud del hablante: prototípicamente el subjuntivo marca la falta de compromiso del hablante frente a lo enunciado, ya sea por el uso del estilo indirecto (38) o por la falta de control que tiene frente al estado de cosas descrito por el subjuntivo (42).

(42) No supuse que jugaran con el dinero. 
En (42), jugar con el dinero es un evento que no está determinado por el emisor y que rompe sus expectativas. Aquí el rasgo semántico y el rasgo pragmático se imponen sobre el tiempo y otros rasgos semánticos (factualidad).

El subjuntivo refleja también una evaluación positiva o negativa del evento descrito por parte del emisor (rasgo pragmático) o por parte del sujeto de la oración principal (rasgo gramatical). Puede estar inducido por los llamados verbos emotivos del tipo: gustar, temer, desear o por expresiones que señalan una valoración: es increíble, es improbable, etc. La valoración puede darse si el evento ya ocurrió, ocurre o va a ocurrir.

(43) Me alegro de que hayas llegado bien.

(44) Me gusta que vayas a la Universidad.

Con este verbo y otros de significado similar se encuentran alternancias con el indicativo.

(45) Se alegrarán mucho si puedes ir a verlos.

Con el indicativo el emisor compromete al receptor, a pesar de la estructura de condicionalidad. Obsérvese la relación entre el futuro del verbo principal y la posterioridad y posibilidad del verbo subordinado.

Atenuación: el subjuntivo se emplea como mecanismo de cortesía:

(46) Quisiera que me envíen el resultado del examen a mi casa.

En (46) es claro que el hablante quiere el resultado; podría haber usado el indicativo, pero dada su posición de subordinación frente al destinatario usa el subjuntivo como mecanismo de atenuación de la intención comunicativa. Por medio de la atenuación se establece una relación positiva entre los dos interlocutores; el emisor busca la aceptación del receptor para conseguir lo que pretende.

Obsérvese que en (46) también están presentes varios de los rasgos que hemos visto: dos sujetos y dos interlocutores (emisor, receptor), posterioridad, posibilidad, etc.

\section{Discusión y conclusiones}

De acuerdo con los rasgos y con el análisis del corpus se encontró que la estructura de subjuntivo prototípica es la que expresa un evento donde hay involucrados dos sujetos gramaticales, donde el sujeto de la oración principal no tiene control sobre lo que realizará el segundo sujeto y donde el evento expresado por el subjuntivo es posterior al del evento del verbo principal.

Estos rasgos hacen que los hechos descritos en el subjuntivo sean probables, inciertos, irreales, no factuales (ya sea de forma representativa -no reales- o evaluados como no factuales por parte del emisor). En términos de Alarcos Llorach (1994), el modo de la irrealidad.

Estas construcciones suelen estar precedidas de un conector que no se puede omitir con facilidad.

Ejemplo de esta prototipicidad son las oraciones finales de subjuntivo, que cumplen con la mayoría de los rasgos previamente descritos. Las oraciones completivas suelen alternar entre el subjuntivo e indicativo: las que aparecen en subjuntivo están en una escala de prototipicidad alta cuando están relacionadas con el estilo indirecto (verbos de pedir, decir) o con verbos que expresan algún tipo de valoración o emoción: temer o gustar (RAE, 2009; Ridruejo, 1999). La mayoría de oraciones de relativo aparecen con indicativo; por tanto, las oraciones relativas con subjuntivo son poco frecuentes y el rasgo decisorio es efectivamente la inespecificidad ( $c f$. Pérez, 1999). Es frecuente el uso del subjuntivo en oraciones concesivas expresadas por aunque o por variantes del tipo así, a pesar de que.

Las construcciones de subjuntivo menos prototípicas reportan un evento factual, anterior (o simultáneo) al acto de habla o al hecho principal, donde el sujeto (gramatical) o el hablante (participante comunicativo) no tuvo ningún tipo de participación y por tanto la acción no dependió de él y donde hay una valoración velada (puede ser negativa o positiva). Hay un número importante de verbos de sentimiento y valoración incluidos en ellos. En algunos casos el subjuntivo expresa 
un valor atemporal y una cierta indefinitud, lo que puede explicar la presencia del subjuntivo.

Gramáticas de la lengua española como la de la RAE (2009) y autores como Bello (1847), Alcina y Blecua (1975), Fernández (1986), Bosque (1990), Moreno (1991) y Alarcos (1994), ya habían caracterizado el subjuntivo a partir de algunos de los rasgos encontrados en la presente investigación, sobre todo lo referente a los rasgos semánticos y a los tipos de verbos asociados con el subjuntivo. No obstante, lo que se constata en el análisis del corpus es que un solo rasgo no es decisivo para poner el predicado en subjuntivo; es necesario al menos dos rasgos pues con frecuencia se condicionan mutuamente. Por ejemplo, prototípicamente el rasgo de control es un rasgo sintáctico que tiene su correlato en la no factualidad o también en la no voluntad. Se encontró también que la ausencia de un rasgo, no implica que no aparezca el subjuntivo.

Es de destacar que los datos muestran que un rasgo que caracteriza al subjuntivo es el que hemos llamado de atemporalidad o de indefinitud verbal (no nominal), rasgo que coincide en parte con la hipótesis de Igualada (1998) frente a la ausencia de información temporal del subjuntivo. Y no es que el subjuntivo no indique prototípicamente posterioridad, pero en la mayoría de contextos la información es ambigua o mejor inconcreta. Por ejemplo, en la oración (44), no se sabe si es ahora, en el pasado o en el futuro.

El aporte principal de este estudio es ver el subjuntivo de manera integral a partir de los distintos niveles de lengua y a partir de unos rasgos. Rasgos del subjuntivo como la falta de control, la atemporalidad, la relación con el estilo indirecto o los valores aspectuales a los que está unido, son también aportes de este trabajo.

El subjuntivo es un modo muy curioso, marca por una parte que la acción descrita en este modo no depende del sujeto gramatical central o del emisor (acto comunicativo) y por tanto puede o no darse y que cuando se da rompe las expectativas del emisor (plano pragmático) o del sujeto de la oración principal (plano gramatical) o sirve para expresar su juicio, el cual, por supuesto, puede ser objetable. De manera inversa, el subjuntivo marca también que el segundo sujeto o el receptor no tuvo control sobre el evento descrito o no quiso hacerlo. Cuando expresa un evento factual, en la mayoría de las veces, el que no tiene control es el sujeto gramatical de la oración principal o el emisor del acto de habla.

\section{Referencias}

Alarcos, E. (1994). Gramática de la lengua española. Madrid: Espasa Calpe.

Alcina, J. y Blecua, J. (1975). Gramática española. Barcelona: Ariel.

Bello, A. (1847). Gramática de la lengua castellana destinada al uso de los americanos. Tenerife: Trujillo.

Bickel, B. (2010). Capturing particulars and universals in clause linkage: a multivariable analysis. En I. Bril (ed.), Clause hierarchy and clause linking: the syntax and pragmatics interface (pp. 51-101). Ámsterdam: Benjamins.

Bosque, I. (1990). Indicativo y subjuntivo. Taurus: Madrid. Dik, S. (1997). The Theory of Functional Grammar. 2 vols. Berlín: Mouton de Gruyter.

Fernández Ramírez, S. (1986). Gramática española: el verbo y la oración. Vol. 4 (ordenado y completado por Ignacio Bosque). Madrid: Arco-Libros.

García-Miguel, J. (1995). Transitividad y complementación preposicional en español. España: Universidad de Santiago de Compostela.

Gili Gaya, S. (1994). Curso superior de sintaxis española. Barcelona: Vox.

Hopper, P. y Thompson, S. (1980). Transitivity in Grammar and Discourse. Language, 56, 251-299.

Igualada, B. (1989). Nueva hipótesis sobre el subjuntivo en español. Estudios Románicos, 4, 643-663.

Lazard, G. (2002). Transitivity revisited as an example of a more strict approach in typological research. Filia Lingüística, 3(4), 141-190.

Lizárraga, G. y Mora-Bustos, A. (2010). Variación en la marcación diferenciada de objeto en español. Forma y Función, 23(1), 9-38.

Mora-Bustos, A. (2005). El aspecto composicional. En C. Ramírez y M. Islas (comp.), Sintaxis del español e interfase sintaxis semántica (pp. 91-107). México: Universidad Autónoma del Estado de México. 
Mora, A. (2013). Variación gramatical en los adjuntos oracionales. En S. Bogard (ed.), Del léxico al discurso. La construcción gramatical del sentido en español. México: El colegio de México.

Mora-Bustos, A. (2004). La transitividad en construcciones oracionales constituidas por un verbo matriz y un objeto oracional subordinado introducido por 'que'. Tesis doctoral. El Colegio de México, México.

Moreno, J. (1991). Curso universitario de lingüística general. Madrid: Editorial Síntesis.

Ochoa, L. (2009). Verbos latinos intransitivos de régimen dativo. Bogotá: Universidad Nacional de Colombia.

Palmer, F.(1986). Mood and modality. Cambridge: Cambridge University Press.

Pérez, M. (1999). El modo en las subordinadas relativas y adverbiales. En I. Bosque y V. Demonte. Gramática descriptiva de la lengua española (pp. 3253-3322, vol. II). Madrid: Espasa Calpe.

Real Academia Española (RAE). (2009). Nueva Gramática de la lengua española. Madrid: Espasa.

Ridruejo, E, (1999). Modo y modalidad. El modo en las subordinadas sustantivas. En I. Bosque y V. Demonte. Gramática descriptiva de la lengua española (pp. 3209-3251, vol. II). Madrid: Espasa Calpe.

Sastre, M. (1999) El subjuntivo en español. Madrid: Colegio de España.

Vásquez, J. (2013). Los modos verbales del español actual. Lingüística y literatura, 63, 255-271.

Vendler, Z. (1957). Verbs and Times. The Philosophical Review, LXVI(1957), 143-160. 